\title{
Robust Output-feedback Control for Piloted Electro-hydraulic Proportional Pressure-reducing Valve
}

\author{
Pan Deng ${ }^{1,2, a}$, Liangcai Zeng ${ }^{1, b}$ \\ ${ }^{1}$ Automatic Mechanical College of Wuhan University of Science and Technology, Wuhan 430081, \\ China \\ ${ }^{2}$ Research \& Development Center of Wuhan Iron \& Steel Corporation, Wuhan 430080, China \\ adengpan390@126.com, bengliangcai@wust.edu.cn
}

Keywords: pressure-reducing valve; observer; output-feedback; robust $\mathrm{H}$-infinity performance.

\begin{abstract}
The paper aims at piloted electro-hydraulic proportional pressure-reducing valve characteristics of uncertain parameters, immeasurable states and effect of load flow, designed an observer including load flow and it's feedback controller ,achieve robust output-feedback control to the output pressure .Based on linear matrix inequalities, theoretical analysis showed that the system was stable and had robust $\mathrm{H}$-infinity performance, given the method to obtain the observer gain $\mathrm{L}$ and controller gain $\mathrm{K}$. By simulating a certain proportional pressure reducing valve, verified the validity of the algorithm, eliminated the influence of load flow to output pressure and ensured it following the set pressure quickly.
\end{abstract}

\section{Introduction}

The excitation system for track subgrade dynamic response test is used for simulating the comprehensive influence of the static load and dynamic load on the subgrade when train running at high speeds, the main unit of test system include dual stage servo hydraulic cylinders and hydraulic vibration system [1-2]. The system supplies constant pressure for static cavity of dual stage servo hydraulic cylinder by using piloted electro-hydraulic proportional pressure reducing valve, used to simulate the static force of train, at the same time the static cavity also be effected by alternating excitation force from dynamic cavity. How to make the static cavity loaded force kept constant, depending on the precise control of the pilot electro-hydraulic proportional pressure reducing valve.

In practical application, usually use open-loop control for electro-hydraulic proportional pressure reducing valve pressure control, because the system parameters are uncertainty and nonlinear, by using conventional control algorithms based on precise mathematical model, the output pressure is difficult to achieve the requirements of fast tracking performance, accuracy and robustness [3-4].

\section{System description}

The piloted electro-hydraulic proportional pressure reducing valve mainly include the amplifier, the proportional electromagnet, pilot poppet valve and three way slide valve [5].

Pilot level modeling. The response frequency of the proportional electromagnet controller is far higher than the proportional pressure reducing valve [6] , and Pilot poppet valve is little quality, small stroke and large elastic stiffness , therefore, obtained for the pilot stage simplified model:

$$
P_{2}=K_{t} U_{g} / A_{x}
$$

Master valve equation [7-8]. The most important operating point of Pressure reducing valve is the origin $(\mathrm{QL}=\mathrm{P} 1=\mathrm{Y}=0)$, if the system is stable in this operating point, it is stable at other operating points. So, the flow equation of master valve:

$$
\frac{V_{2}}{E} \frac{d P_{1}}{d t}=C_{d} \omega \sqrt{P / \rho} Y+A_{1} \frac{d Y}{d t}-Q_{L}
$$

The force balance equation of master spool: 


$$
A_{2} K_{t} U_{g} / A_{x}-P_{1} A_{1}=M \frac{d^{2} Y}{d t}+\left(B+A_{1}^{2} R_{2}\right) \frac{d Y}{d t}+K_{Y 0} Y
$$

Where, $R_{2}$ is the liquid resistance of fixed damper orifice, $N \cdot S / \mathrm{m}^{5} ; Q_{L}$ is the load flow, $\mathrm{m}^{3} / \mathrm{S} ; \mathrm{E}$ is the elastic modulus of oil, $\mathrm{N} / \mathrm{m}^{2} ; \mathrm{P}$ is the supply pressure, $\mathrm{Pa} ; \mathrm{P}_{1}$ is the output pressure, $\mathrm{Pa}$; $\mathrm{P}_{1 \mathrm{~S}}$ is the left cavity pressure of master valve, $\mathrm{Pa}$; $\mathrm{A}_{1}$ is the effective area of the master spool left end , $\mathrm{m}^{2} ; \mathrm{V}_{2}$ is the effective volume connecting master valve outlet and load orifice, $\mathrm{m}^{3} ; \mathrm{C}_{\mathrm{d}}$ master valve port flow coefficient; $\omega$ is the area coefficient; $\rho$ is the oil density, $K_{g} / m^{3} ; M$ is the master spool quality, $K_{g}$; $\mathrm{K}_{\mathrm{Y} 0}$ is the reset spring stiffness coefficient, $\mathrm{N} / \mathrm{m}$; B is the viscous damping coefficient, $\mathrm{N} \cdot \mathrm{s} / \mathrm{m}$; $\mathrm{Y}$ is the master spool displacement, $\mathrm{m}$.

Model description. Set $x_{x}=Y$ as the main spool displacement, $P_{r}$ desired output pressure of the proportional pressure reducing valve, $\mathrm{P}_{1}$ is output pressure measurements. The state variables $\mathrm{x}_{1}=\mathrm{x}_{\mathrm{x}}$, $\mathrm{x}_{2}=\dot{X}_{x}, \mathrm{x}_{3}=\mathrm{P}_{\mathrm{r}}-\mathrm{P}_{1}, \mathrm{X}=\left[\mathrm{x}_{1} \mathrm{x}_{2} \mathrm{x}_{3}\right]^{\mathrm{T}}$, by formula (2) and (3) to obtain the state equation of the system as follows:

$$
\left\{\begin{array}{l}
X_{1}=X_{2} \\
X_{2}=-a_{1} X_{1}-a_{2} X_{2}+a_{3} X_{3}+b b U_{g}-\mathrm{P}_{\mathrm{r} 1}+\Delta_{1} X+\Delta_{3} U_{g}+\Delta_{4} \mathrm{P}_{\mathrm{r}} \\
X_{3}=-a_{4} X_{1}-a_{5} X_{2}+Q_{l k}+\Delta_{2} X
\end{array}\right.
$$

Where, $\mathrm{a}_{1}=\mathrm{K}_{\mathrm{Y} 0} / \mathrm{M}, \mathrm{a}_{2}=\left(\mathrm{B}+\mathrm{A}_{1}{ }^{2} \mathrm{R}_{2}\right) / \mathrm{M}, \mathrm{a}_{3}=\mathrm{A}_{1} / \mathrm{M}, \mathrm{a}_{4}=\mathrm{C}_{\mathrm{d}} \omega \operatorname{sqrt}(\mathrm{P} / \rho) \mathrm{E} / \mathrm{V}_{2}, \mathrm{a}_{5}=\mathrm{A}_{1} \mathrm{E} / \mathrm{V}_{2}, \mathrm{bb}=\mathrm{A}_{2}$ $\mathrm{K}_{\mathrm{t}} /(\mathrm{AxM}), \mathrm{P}_{\mathrm{r} 1}=\mathrm{a}_{3} \mathrm{P}_{\mathrm{r}}, \mathrm{Q}_{\mathrm{lk}}=\mathrm{Q}_{\mathrm{L}} \mathrm{E} / \mathrm{V}_{2}$, above parameter is the basic parameter. $\Delta_{1}=\left[-\mathrm{da}_{1}-\mathrm{da}_{2} \mathrm{da}_{3}\right]$, $\Delta_{2}=\left[-\mathrm{da}_{4}-\mathrm{da}_{5} 0\right], \Delta_{3}=\mathrm{d}_{\mathrm{bb}}, \Delta_{4}=\mathrm{da}_{3}$, is the uncertainty part, and bounded, $\left|\mathrm{da}_{\mathrm{i}}\right| \leq \mathrm{D}_{\mathrm{aj}},\left|\mathrm{d}_{\mathrm{bb}}\right| \leq \mathrm{D}_{\mathrm{bb}}$, $\mathrm{i}=1 \sim 5, \mathrm{D}_{\mathrm{aj}}$ and $\mathrm{D}_{\mathrm{bb}}$ are known positive.

\section{Robust output feedback controller design}

Set the $\zeta_{1}=\mathrm{x}_{1}-\mathrm{Q}_{\mathrm{kk}} / \mathrm{a}_{4}, \zeta_{2}=\mathrm{x}_{2}, \zeta_{3}=\mathrm{x}_{3}, \zeta=\left[\zeta_{1} \zeta_{2} \zeta_{3}\right]^{\mathrm{T}}$, formula (4) can be transformed into:

$$
\left\{\begin{array}{l}
\square=A \varsigma+B\left(U_{g}-S_{5}\right)+D_{1}\left(S_{1}+S_{3}+S_{4}\right)+D_{2} S_{2} \\
y=C \varsigma
\end{array}\right.
$$

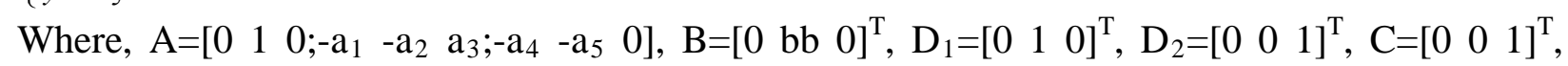
$\mathrm{S}_{1}=\Delta_{1} \zeta-\mathrm{da}_{1} \mathrm{Q}_{\mathrm{lk}} / \mathrm{a}_{4}, \mathrm{~S}_{2}=\Delta_{2} \zeta-\mathrm{da}_{4} \mathrm{Q}_{\mathrm{lk}} / \mathrm{a}_{4}, \mathrm{~S}_{3}=\Delta_{3} \mathrm{U}_{\mathrm{g}}, \mathrm{S}_{4}=-\mathrm{da}_{3} \mathrm{P}_{\mathrm{r}}, \mathrm{S}_{5}=\left(\mathrm{P}_{\mathrm{r} 1}+\mathrm{a}_{1} \mathrm{Q}_{\mathrm{lk}} / \mathrm{a}_{4}\right) / \mathrm{bb}$.

The system state variables only system output $\mathrm{x}_{3}$ can be measured, therefore, need to construct the full-order observer was used to estimate all state variables.

$$
\delta=A \delta+B\left(U_{g}-S_{5}\right)+D_{1} S_{3}+L(y-C \delta)
$$

Where, $\delta$ is the estimated value of $\zeta, L \in \mathbb{R}^{3 \times 1}$ is the observer gain. Estimates error is set as $\varepsilon=\zeta-\delta$, dynamic error equations are as follows:

$$
\varepsilon=A_{11} \varepsilon-L C \varepsilon+D_{1}\left(\Delta_{1} \delta+\theta_{1}\right)+D_{2}\left(\Delta_{2} \delta+\theta_{2}\right)
$$

Where, $\mathrm{A}_{11}=\mathrm{A}+\mathrm{D}_{1} \Delta_{1}+\mathrm{D}_{2} \Delta_{2}, \theta_{1}=\mathrm{S}_{4}-\mathrm{da}_{1} \mathrm{Q}_{\mathrm{lk}} / \mathrm{a}_{4}, \theta_{2}=-\mathrm{da}_{4} \mathrm{Q}_{1 \mathrm{k}} / \mathrm{a}_{4}$.

Based on the full order observer (6), get the robust output feedback controller:

$$
U_{g}=K \delta+S_{5}
$$

The observer can be simplified as:

$$
\delta=\left(A+B_{1} K\right) \delta+B_{2} \theta_{3}+L C \varepsilon
$$

Where, $\mathrm{B}_{1}=\left[0 \mathrm{bb}+\mathrm{d}_{\mathrm{bb}} 0\right]^{\mathrm{T}}, \mathrm{B}_{2}=\left[0 \mathrm{~d}_{\mathrm{bb}} 0\right]^{\mathrm{T}}, \theta_{3}=\mathrm{S}_{5}, \mathrm{~K} \in \mathbb{R}^{1 \times 3}$ is the gain of the feedback controller.

Theorem 1 for the augmented system (7), (9) and given positive $\alpha, \beta_{1}$ and appropriate positive definite diagonal matrix $\lambda_{1}$, if exists symmetric positive real matrix $\mathrm{W} \in \mathbb{R}^{3 \times 3}$ and $\mathrm{V} \in \mathbb{R}^{3 \times 3}$, real matrix $E \in \mathbb{R}^{3 \times 1}$ and $F \in \mathbb{R}^{1 \times 3}$, positive real numbers $R_{11}$ and $R_{12}$, which makes the follows linear matrix inequality has a solution, so $\mathrm{u}(\mathrm{t})=\mathrm{FV}^{-1} \delta(\mathrm{t})+\mathrm{S}_{5}$ is the optimal $\mathrm{H}$-infinity robust control law of this closed loop system composed of $u(t)$ and the augmented system (7), (9), also make the closed loop system bounded. 


$$
\begin{aligned}
& \min _{W, E, R_{11}} R_{11} \\
& \text { s.t. }\left[\begin{array}{ccc}
\Psi_{1} & W D_{1} & W D_{2} \\
D_{1}^{T} W & -\frac{R_{11}}{2} & 0 \\
D_{2}^{T} W & 0 & -\frac{R_{11}}{2}
\end{array}\right] \leq 0 \\
& \min _{V F . R_{1}, N} \operatorname{Trace}(N) \\
& \text { s.t. }(i)\left[\begin{array}{cccc}
\Psi_{2} & B_{2} & V \Delta_{11}^{T} & V \Delta_{22}^{T} \\
B_{2}^{T} & -R_{12} & 0 & 0 \\
\Delta_{11} V & 0 & -R_{11}^{-1} & 0 \\
\Delta_{22} V & 0 & 0 & -R_{11}^{-1}
\end{array}\right] \leq 0 \\
& \text { (ii) }\left[\begin{array}{ccc}
-N & F^{T} \\
F & -I
\end{array}\right]
\end{aligned}
$$

Where, $\Delta_{11}=\left[\begin{array}{lll}\mathrm{D}_{\mathrm{a} 1} & \mathrm{D}_{\mathrm{a} 2} & \mathrm{D}_{\mathrm{a} 3}\end{array}\right], \Delta_{22}=\left[\begin{array}{ll}\mathrm{D}_{\mathrm{a} 4} & \mathrm{D}_{\mathrm{a} 5} 0\end{array}\right], \Psi_{1}=\mathrm{A}_{11}{ }^{\mathrm{T}} \mathrm{W}+\mathrm{WA} \mathrm{A}_{11}-\mathrm{EC}-\mathrm{C}^{\mathrm{T}} \mathrm{E}+\alpha \mathrm{W}+\lambda_{1}$, $\Psi_{2}=\mathrm{VA}^{\mathrm{T}}+\mathrm{AV}+\mathrm{B}_{1} \mathrm{~F}+\mathrm{F}^{\mathrm{T}} \mathrm{B}_{1}{ }^{\mathrm{T}}+\alpha \mathrm{V}+\mathrm{LCC}^{\mathrm{T}} \mathrm{L}^{\mathrm{T}} / \beta_{1}$.

By the calculated real symmetric positive matrices $\mathrm{W}$ and $\mathrm{V}$, real matrix $\mathrm{E}$ and $\mathrm{F}$, we can get the observer gain $\mathrm{L}=\mathrm{W}^{-1} \mathrm{E}$ and controller gain $\mathrm{K}=\mathrm{FV}^{-1}$.

Proof: select Lyapunov function $\mathrm{Z}(\varepsilon, \delta)=\mathrm{Z}(\varepsilon)+\mathrm{Z}(\delta)=\varepsilon^{\mathrm{T}} \mathrm{W} \varepsilon^{+} \delta^{\mathrm{T}} \mathrm{Q} \delta$, where $\mathrm{Q}$ is a symmetric positive definite matrix.

The time derivative of estimation error:

$$
Z(\varepsilon)=\dot{\varepsilon}^{T} W \varepsilon+\varepsilon^{T} W \dot{\varepsilon}=\varepsilon^{T}\left(A_{11}^{T} W+W A_{11}-(L C)^{T} W-W L C\right) \varepsilon+2 \varepsilon^{T} W D_{1}\left(\Delta_{1} \delta+\theta_{1}\right)+2 \varepsilon^{T} W D_{2}\left(\Delta_{2} \delta+\theta_{2}\right)
$$

By the correlation lemma shows that the existence of any positive scalar $R_{11}$, satisfies the following inequalities:

$$
\begin{aligned}
& 2 \varepsilon^{T} W D_{1}\left(\Delta_{1} \delta+\theta_{1}\right) \leq 2 R_{11}^{-1} \varepsilon^{T} W D_{1} D_{1}^{T} W \varepsilon+R_{11} \delta^{T} \Delta_{11}^{T} \Delta_{11} \delta+R_{11} \theta_{1}^{2} \\
& 2 \varepsilon^{T} W D_{2}\left(\Delta_{2} \delta+\theta_{2}\right) \leq 2 R_{11}^{-1} \varepsilon^{T} W D_{2} D_{2}^{T} W \varepsilon+R_{11} \delta^{T} \Delta_{22}^{T} \Delta_{22} \delta+R_{11} \theta_{2}^{2}
\end{aligned}
$$

Set $E=W L$, feeding the formula (13), (14) into (12), by linear inequality (10), fined that:

$Z(\varepsilon) \leq-\alpha Z(\varepsilon)-\varepsilon^{T} \lambda_{1} \varepsilon+R_{11} \theta_{\varepsilon}$

In the formula, $\theta_{\varepsilon}=\delta^{T} \Delta_{11}^{T} \Delta_{11} \delta+\delta^{T} \Delta_{22}^{T} \Delta_{22} \delta+\theta_{1}^{2}+\theta_{2}^{2}$ is disturbance quantity caused by parameter uncertainty part, select the smallest positive real number $\mathrm{R}_{11}$, we can ensure that the disturbance to observer caused by parameter uncertainty part, is reduced to a minimum, so that the observer can accurately estimate the system state.

The time derivative of observer estimate variable:

$$
Z(\delta)=\dot{\delta}^{T} Q \delta+\delta^{T} Q \dot{\delta}=\delta^{T}\left(\left(A+B_{1} K\right)^{T} Q+Q\left(A+B_{1} K\right)\right) \delta+2 \delta^{T} Q L C \varepsilon+2 \delta^{T} Q B_{2} \theta_{3}
$$

There have any positive scalar $\mathrm{R}_{12}$ and $\beta_{1}$, satisfy the following inequalities:

$2 \delta^{T} Q L C \varepsilon \leq \beta_{1}^{-1} \delta^{T} Q L C C^{T} L^{T} Q \delta+\beta_{1} \varepsilon^{T} \varepsilon$

$2 \delta^{T} Q B_{2} \theta_{3} \leq R_{12}^{-1} \delta^{T} Q B_{2} B_{2}^{T} Q \delta+R_{12} \theta_{3}^{2}$

Set $\mathrm{V}=\mathrm{Q}^{-1}, \mathrm{~F}=\mathrm{KV}$, by linear inequality (11), fined that:

$Z(\delta) \leq-\alpha Z(\delta)+\beta_{1} \varepsilon^{T} \varepsilon-R_{11} \theta_{\delta}+R_{12} \theta_{3}^{2}$

Where $\theta_{\delta}=\delta^{T} \Delta_{11}^{T} \Delta_{11} \delta+\delta^{T} \Delta_{22}^{T} \Delta_{22} \delta$.

According to formula (15), (19), obtained the time derivative of system Lyapunov function is:

$Z(\varepsilon, \delta)=Z(\varepsilon)+Z(\delta) \leq-\alpha Z(\varepsilon, \delta)-\varepsilon^{T}\left(\lambda_{1}-\beta_{1}\right) \varepsilon+R_{11}\left(\theta_{1}^{2}+\theta_{2}^{2}\right)+R_{12} \theta_{3}^{2}$

From the inequality (20),we can found that, if choices appropriate parameters $\alpha, \beta_{1}$ and $\lambda_{1}$, estimation error $\varepsilon$ and estimated value $\delta$ all converged to finite bounds determined by $\mathrm{R}_{11}$ and $\mathrm{R}_{12}$, so that the closed-loop system composed of the controller (8) and the augmented system (7), (9), are bounded, and has a robust $\mathrm{H}$-infinity performance. In addition, minimize $\mathrm{R}_{11}$, select the appropriate $\mathrm{R}_{12}$, through the Trace $\left(\delta^{\mathrm{T}} \mathrm{K}^{\mathrm{T}} \mathrm{K} \delta\right.$ ), the amplitude of controller output is minimized, thus its magnitude 
is limited in the range of the valve control input signal, and disturbance caused by the parameters uncertain part is inhibite to the narrow limits. Theorem 1 is proved.

\section{Simulation examples}

Through the simulation of a certain proportional pressure reducing valve as an example, to verify the effectiveness of the robust output feedback control method. The physical parameters of the proportional pressure reducing valve as follow: $\mathrm{K}_{\mathrm{t}}-7 ; \mathrm{K}_{\mathrm{Y} 0}-1 \mathrm{e}^{4} \mathrm{~N} / \mathrm{m} ; \omega-0.036 \mathrm{~m} ; \mathrm{C}_{\mathrm{d}}-0.7 ; \mathrm{B}-5$ $\mathrm{NS} / \mathrm{m} ; \mathrm{R}_{2}-4.07 \mathrm{e}^{9} \mathrm{NS} / \mathrm{m}^{5} ; \mathrm{P}-2.06 \mathrm{e}^{7} \mathrm{~Pa} ; \mathrm{A}_{\mathrm{X}}-3.14 \mathrm{e}^{-6} \mathrm{~m}^{2} ; \rho-850 \mathrm{~kg} / \mathrm{m}^{3} ; \mathrm{E}-9 \mathrm{e}^{8} \mathrm{~N} / \mathrm{m}^{2} ; \mathrm{A}_{1}-2.94 \mathrm{e}^{-4}$ $\mathrm{m}^{2} ; \mathrm{A}_{2}-2.94 \mathrm{e}^{-4} \mathrm{~m}^{2} ; \mathrm{M}-0.16 \mathrm{Kg} ; \mathrm{V}_{2}-5 \mathrm{e}^{-3} \mathrm{~m}^{3}$.

The uncertain parameters are set to $\mathrm{da}_{1}=300, \mathrm{da}_{2}=50, \mathrm{da}_{3}=1 \mathrm{e}^{-4}, \mathrm{da}_{4}=2000, \mathrm{da}_{5}=500, \mathrm{~d}_{\mathrm{bb}}=175.7$, and the upper bound are $\mathrm{D}_{\mathrm{a} 1}=500, \mathrm{D}_{\mathrm{a} 2}=100, \mathrm{D}_{\mathrm{a} 3}=1 \mathrm{e}^{-4}, \mathrm{D}_{\mathrm{a} 4}=5000, \mathrm{D}_{\mathrm{a} 5}=2000, \mathrm{D}_{\mathrm{bb}}=175.7$.

Set the proportional pressure reducing valve setting pressure is $\mathrm{P}_{\mathrm{r}}=1.2 \mathrm{e}^{7} \mathrm{~Pa}$, the amplitude of load flow is $\mathrm{Q}_{\mathrm{L}}=1.67 \mathrm{e}^{-3} \mathrm{~m}^{3} / \mathrm{s}$, we can get the system initial $\zeta(0)=\left[\begin{array}{lll}0 & 0 & \mathrm{P}_{\mathrm{r}}\end{array}\right]^{\mathrm{T}}$ and the observer initial $\delta(0)=$ $\left[\begin{array}{lll}0 & 0 & \mathrm{P}_{\mathrm{r}}\end{array}\right]^{\mathrm{T}}$. According to theorem 1 , given the simulation data are $\alpha=0.2, \beta_{1}=1 \mathrm{e}^{5}$ and $\lambda_{1}=\operatorname{diag}\left(\left[2 \mathrm{e}^{2} 4 \mathrm{e}^{1}\right.\right.$ $\left.1.32 \mathrm{e}^{9}\right]$ ), by formula (10) and (11) we can get: $\mathrm{R}_{11}=4.9 \mathrm{e}^{-11}, \mathrm{R} 12=0.067, \mathrm{~L}=\left[-629.5 ;-1.2987 \mathrm{e}^{13}\right.$; $\left.3.489 \mathrm{e}^{10}\right], \mathrm{K}=\left[-1.7039 \mathrm{e}^{9}-1.2745 \mathrm{e}^{5} 0.046597\right]$.

Substitute the observer gain L and controller gain K into formula (7), (9), and constitute a robust output feedback closed-loop system with the original system (5), using Mat lab to simulate the system when the load flow was $20 \mathrm{~Hz}$ sine signal $\mathrm{Q}_{\mathrm{L} 2}=\mathrm{Q}_{\mathrm{L}}\left(1-\cos \left(40 * \mathrm{pi}^{*} \mathrm{t}\right)\right) / 2$, get the curve of observer output and system state response, shown in figure 1 . We can see that the observer and the robust controller can not only adapt to the change of load flow, rapid estimate the observed state, but also can guarantee the system output pressure quickly reach the set pressure, and has very strong robustness to parameter perturbation.
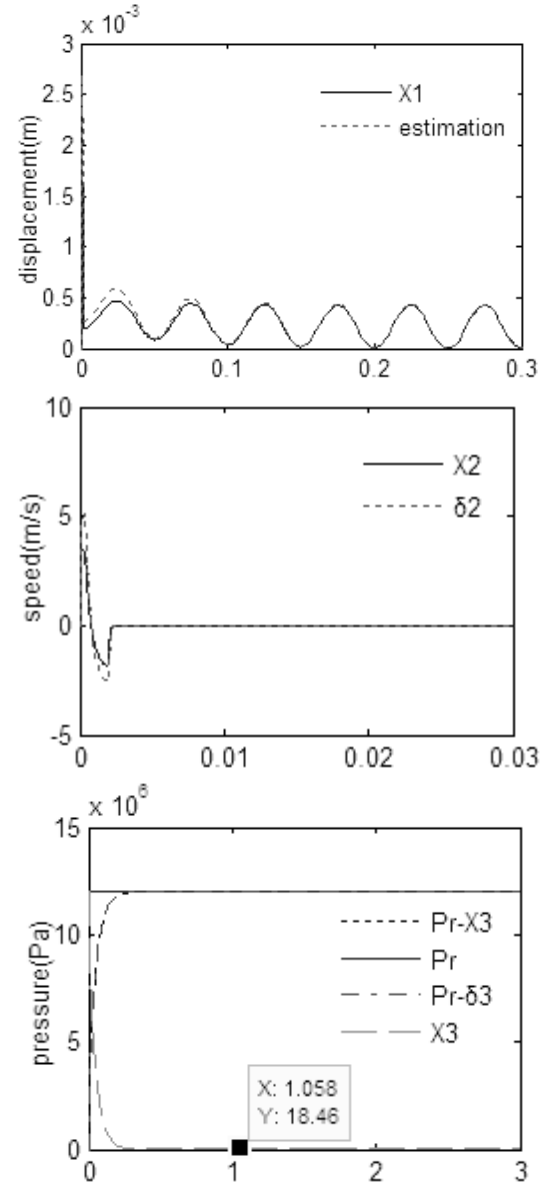

Fig1 the simulation curve of sine load flow 


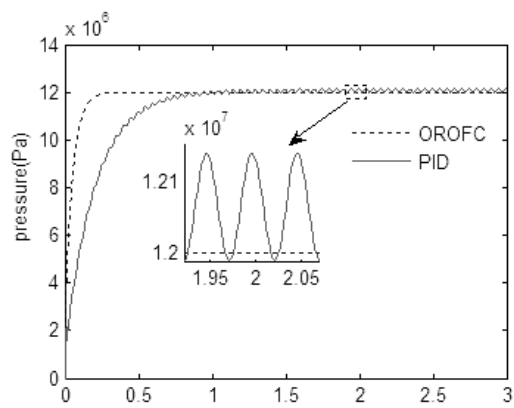

Fig 2 the output pressure of robust output feedback control and PID control

When the load flow was sine signals, we compared the simulation result of the proportional pressure reducing valve with robust output feedback control and PID control, simulation curve as shown in figure 2. We can see that the robust output feedback control has a good dynamic performance of fast response, non-overshoot, response curve smoothing and so on, and the static performance of convergence, and small steady-state error. When system load flow is above sine signal, robust output feedback control existed only 18.45Pa small pressure deviation between the output pressure and the set pressure, while the amplitude pressure deviation of PID control was up to $1.54 \mathrm{e}^{5} \mathrm{~Pa}$. Therefore, in terms of proportional pressure reducing valve, the robust output feedback control has better dynamic and static performance comparing with the conventional feedback control.

\section{Conclusion}

Aim at the characteristics of proportional pressure reducing valve pressure control system with uncertain parameters, immeasurable states and effect of load flow, this paper proposed a robust output-feedback control algorithm based on state observer. Firstly, constructed an observer contain load flow, designed a robust output feedback controller to control the valve output pressure. Secondly, by using the linear matrix inequality, in theory, proposed the control method could guarantee the system stability and had robust $\mathrm{H}$-infinity performance, and given the methods to obtain the observer gain $\mathrm{L}$ and controller gain K. Finally, through the simulation of a certain proportional pressure reducing valve, verified the validity of the control algorithm, compares with traditional feedback control, it could not only eliminate the influence of load flow to output pressure , but also made proportional pressure reducing valve having better dynamic and static performance.

\section{Reference}

[1] Zeng Liang-cai, Chen Chang-long, Chen Xin-yuan, et al. Design of hydraulic excitation system for dynamic response testing of railway subgrade [J]. Chinese Hydraulics \& Pneumatics, 2012, (4): $9-10$.

[2] Li Peng, Chen Xin-yuan, Wan Yuan, et al. Research on pressure servo valve of rail track dynamic test excitation system [J]. Chinese Hydraulics \& Pneumatics, 2013, (8): 62-65.

[3] Wang Guo-dong, Yan Xiang-an, Xiao Ju-liang, et al. Grey prediction fuzzy control for electrohydraulic proportional pressure control system [J]. Journal of China Coal Society, 2006, (8):525-528.

[4]Liu Chang-bin, Yue Ji-guang. Research on neural network controller with grey prediction model using electro-pneumatic proportional pressure valve [J]. Chinese Hydraulics \& Pneumatics, 2009, (3):26-28.

[5]Xu Yi-ming. Electro hydraulic proportional control system analysis and design [M]. Beijing: China Machine Press, 2005.

[6] Yao Jia. The investigation on dynamic characteristics for direct operated electro -hydraulic three way proportional reducing valve [J]. Hydraulics Pneumatics \& Seals, 2013, (2):24-26.

[7]He Cun-xing. Hydraulic components [M]. Beijing: China Machine Press, 1982.

[8] Merritt, Chen Yan-qing. Hydraulic control system [M]. Beijing: Science Press, 1976. 